\title{
RESEARCH
}

\section{Pregnancies associated with etonogestrel implants in the UK: comparison of two five-year reporting periods}

\author{
Sam Rowlands ${ }^{1}$ \\ Emma Cornforth ${ }^{2}$ \\ Mira Harrison-Woolrych ${ }^{3}$
}

${ }^{1}$ Centre of Postgraduate Medical Research and Education, Faculty of Health and Social Sciences, Bournemouth University, R506 Royal London House, Christchurch Road, Bournemouth BH1 3LT, UK Email: srowlands@bournemouth.ac.uk

\footnotetext{
${ }^{2}$ Medicines and Healthcare products Regulatory Agency, 10 South Colonnade, Canary Wharf, London E14 4PU, UK Email: emma.cornforth@mhra.gov.uk

${ }^{3}$ International Society of Pharmacovigilance, 140 Emmanuel Road, London SW12 OHS, UK Email: miraharrison-woolrych@outlook.com
}

Correspondence to Professor Sam Rowlands

Keywords: contraceptive implant, pregnancy, non-insertion, drug interaction

Word count Abstract 214 words; main text 2,519 words 


\section{ABSTRACT}

Objectives (1) To identify pregnancies associated with use of the contraceptive implants Implanon and Nexplanon in the UK during two five-year reporting periods. (2) To classify the possible reasons for device failure in cases reported for each implant. (3) To examine any differences between reasons for pregnancies associated with these products.

Study design Extraction of data from the UK spontaneous reporting system for adverse drug reactions in relation to etonogestrel implants. Reports indicating pregnancy were identified for the periods 2005-2009 (Implanon) and 2012-2016 (Nexplanon). Possible reasons for failure of the method in each reported case were assigned to one of eight pre-determined categories.

Results After exclusions, 229 Implanon cases and 234 Nexplanon cases contained sufficient information for analysis. True method failures accounted for a majority of the pregnancies in those using contraceptive implants (58\%); the next most common cause was missing implants ( $26 \%$ of pregnancies). In all categories of case there was no difference in frequency of pregnancy when the two time periods were compared.

Conclusions There is still potential for greater avoidance of pregnancies associated with etonogestrel implant use.

Implications This study underscores the continuing need for taking a full drug history, timing the insertion on days $1-5$ or according to recommended quick starting routines and palpating the arm after implant insertion. 


\section{Key messages}

- Although etonogestrel implants are a highly effective form of long-acting reversible contraception, unintended pregnancies continue to be reported in post-marketing use.

- The main reasons for contraceptive failure of etonogestrel devices in 'real life' use include true method failure, missing implants (most likely due to non-insertions) and drug interactions.

- The proportion of failures for each device were not significantly different for Nexplanon when compared to Implanon 


\section{INTRODUCTION}

Etonogestrel implants (Implanon and Nexplanon or Implanon NXT) are highly effective methods of contraception with a licensed lifespan of three years. Combined data from 13 clinical trials of Implanon showed no pregnancies during 4,103 woman-years of exposure; the Pearl Index observed was 0.00 (95\% confidence limits: $0.00-0.09)^{1}$. Despite being a highly effective form of long-acting reversible contraception with a failure rate of less than one pregnancy per 1,000 implants inserted over three years ${ }^{2}$, pregnancies are regularly reported in post-marketing use.

Concerns about failure to locate etonogestrel implants after insertion have highlighted the risks of deep insertion, migration in the arm and intravascular embolism ${ }^{34}$. Impalpable implants may confer a risk of pregnancy if the implant has not been inserted ${ }^{5-7}$ or has been extruded/expelled ${ }^{8-12}$. Previous pharmacovigilance reviews, mainly of Implanon, revealed that some pregnancies were associated with missing implants due to non-insertion: that is failure to insert the implant and failure to recognise that this has happened ${ }^{13-15}$.

The single-rod etonogestrel implant Implanon was available in the UK between 1999 and 2010. In 2005, publications from spontaneous reporting in Australia and France, were the first to identify the issue of missing implants ${ }^{13} 14$. The development of a modified radiopaque implant and applicator (proprietary name Nexplanon) licensed in the UK in $2010^{16}$, made imaging and evaluation of these 'lost implants' more straightforward. Pregnancies in etonogestrel implant users are rare but continue to be reported to the UK's Yellow Card Scheme (https://yellowcard.mhra.gov.uk/). There is little information reported so far on failures of Nexplanon.

In this study, a comparison of spontaneous reports of unintended pregnancies associated with Implanon and Nexplanon devices during two five-year periods was undertaken, in order to investigate whether problems with insertion, in particular non-insertions, have been resolved by the introduction of Nexplanon and its modified applicator. During this time, it is estimated that more than 150,000 implants were prescribed in the UK each year ${ }^{17}$.

\section{METHODS}


Individual case reports of suspected adverse reactions are sent to regulators spontaneously by healthcare professionals and patients through the UK's Yellow Card Scheme ${ }^{18}$. Clinical information provided in these reports is analysed by the UK Medicines and Health products Regulatory Agency (MHRA) and used to detect possible links between a medicine and an adverse effect ${ }^{19}$. Data derived from Yellow Cards and pharmaceutical companies are publicly available for each medicine in the form of interactive Drug Analysis Profiles (https://yellowcard.mhra.gov.uk/idap). The inclusion of a reported reaction in a Drug Analysis Print does not necessarily mean it has been caused by the medicine, only that the reporter had a suspicion it may have been.

Cases of pregnancy in association with the use of Implanon and Nexplanon reported to the MHRA were identified for the periods 2005-2009 (Implanon) and 2012- 2016 (Nexplanon). Since Nexplanon was launched towards the end of 2010 in the UK, the first quinquennium of reporting comprises solely Implanon devices and the second quinquennium almost entirely Nexplanon devices.

\section{Patient and public involvement}

As the study was conducted based on secondary data, contraceptive users and the public were not involved in the design of the study.

\section{Inclusion and exclusion criteria}

All UK spontaneous reports in the MHRA database were screened to identify reporting of pregnancy, from any source - e.g. healthcare professionals, patients or the pharmaceutical industry - occurring with etonogestrel devices. Pregnancy may have been diagnosed clinically at any time, or by the reporter stating that a miscarriage, ectopic pregnancy, termination of pregnancy or delivery had occurred.

The following reports were excluded:

- All reports from other countries

- UK reports where the type of device was not specified

- Duplicate entries 


\section{Assessment of reports}

All cases were reviewed in accordance with a predefined Standard Operating Procedure developed prior to the start of assessment. Two assessors ( $\mathrm{EC}$ and $\mathrm{MH}-\mathrm{W}$ ) were involved in retrospectively reviewing spontaneous reports of pregnancy associated with either device during the two reporting periods. All cases were reviewed independently by at least one assessor and a subsample were assessed by two assessors to ensure consistency of assessment and decision-making. A third assessor (SR) was used for consultation on more complex cases. Reports were assessed to determine whether there was sufficient information to meet the following criteria:

1) Sufficient evidence of pregnancy (cases where patients reported symptoms, but a pregnancy test was negative or never confirmed were excluded)

2) The estimated conception date was after the date of implant insertion (cases where conception occurred prior to implant insertion were excluded)

The following additional aspects of each report were considered in order to determine the possible reason for failure of the implant:

- concomitant medication: all reported medications (prescribed and non-prescribed) were reviewed, along with dates of administration.

- absence of the implant: evidence that the implant was missing included information about being unable to palpate the implant, imaging results and/or blood etonogestrel levels being negative. In the absence of such information the implant was assumed to be present.

For the remaining cases, reasons for failure of the method were placed into pre-determined categories (see Table 1) and statistical comparisons (using Chi-squared and Fisher's Exact test) were made between the Implanon and Nexplanon groups. 
Table 1

Summary of the reasons for implant failure during post-marketing use of Implanon (2005-2009) and Nexplanon (2012-2016)

\begin{tabular}{|c|c|c|c|}
\hline Assessment Category & Implanon $^{1}$ & Nexplanon $^{1}$ & Chi-squared \\
\hline Missing implant ${ }^{2}$ & $68(30 \%)$ & $52(22 \%)$ & $P=0.08$ \\
\hline Drug interaction ${ }^{3}$ & $22(10 \%)$ & $9(4 \%)$ & $\mathrm{P}=0.02$ \\
\hline True method failure ${ }^{4}$ & 122 (53\%) & $148(63 \%)$ & $\mathrm{P}=0.04$ \\
\hline Wrong timing of insertion & $17(7 \%)$ & $18(8 \%)$ & $P=1.00$ \\
\hline Other $^{5}$ & $0(0 \%)$ & $7(3 \%)$ & $\mathrm{P}=0.02^{\mathrm{a}}$ \\
\hline Total & 229 & 234 & \\
\hline
\end{tabular}

${ }^{a}$ Fisher's Exact test

Notes

1. Numbers of cases reported (percentages of total for each group).

2. A missing implant was defined as one not in the body at the time pregnancy was diagnosed.

3. Includes with anti-epileptic, anti-retroviral, anti-tubercular drugs and St. John's wort

4. This category was assigned if no other reason for pregnancy could be determined

5. Included device expelled, damaged/broken device, placebo device inserted

\section{RESULTS}

A total of 831 cases reporting pregnancy ( 377 for Implanon and 454 for Nexplanon) were retrieved from the database and reviewed. Of these, 463 (229 for Implanon and 234 for Nexplanon) were suitable for analysis (see Figure 1). 


\section{Figure 1 Cases suitable for analysis}

[See separate file]

A summary of the reasons for implant failure for both devices is shown in Table 1. True method failures accounted for the majority of pregnancies, with the next most common cause being missing implants. The frequency of each category of pregnancy cause was not significantly different when Implanon and Nexplanon were compared (Table 1).

\section{Missing implants}

Of 68 missing Implanon cases, only 11 contained information about palpation of the implant after insertion and in three of these the implant was never palpable. In addition, eight cases reported infection at the site of insertion; in five of these cases the implant was palpable after insertion.

Of the 52 missing Nexplanon implant cases, 13 contained information about palpation of the implant after insertion. In five of these cases the implant could not be palpated; in seven of the eight cases in which the implant was palpable, an infection at the site of insertion was also reported.

\section{Drug interactions}

Of the 22 cases reported as possible drug interaction with Implanon, the drugs involved were carbamazepine, topiramate, rifampicin, St John's wort and HIV medicines. Of the nine cases of drug interaction associated with Nexplanon, the most commonly reported suspect drugs were HIV medicines, carbamazepine, rifampicin and St John's Wort. The reports did not provide detailed information on the constituent drugs in the HIV medicines. 
Other device failures were applicable to Nexplanon only ( $n=7,3 \%$ of Nexplanon reports). Two reports indicated the implant had been expelled and four cases reported a damaged or broken implant. In one case a placebo device had been inserted in error.

\section{DISCUSSION}

The source data for this study comprising 10 years' experience of UK spontaneous reporting for etonogestrel implants and analysis of 463 reports of device failure make it the largest study of its kind to date. Continuing reports of unintended pregnancy show how 'real-life' use of etonogestrel implants is not associated with the zero-failure rate seen in the clinical trials and how contraceptive failures still occur, despite familiarity of clinicians with the method and design changes to the implant/applicator in 2010. Reasons for device failure included failure to exclude pregnancy prior to insertion, failure to quick start correctly ${ }^{20}$, non-insertion and recognised drug interactions, which are all avoidable causes of pregnancy during implant use.

It has been postulated that human factors may be at work in cases of non-insertion ${ }^{21}$. These types of medical errors could include a 'learning curve' effect, implying that as soon as clinicians become familiar with the method, errors will tend to diminish. Risk management programmes have been set up $^{22}$ and 'top tips' offered to address this ${ }^{2324}$ but our study suggests problems with implant insertion have persisted with the re-designed Nexplanon device.

\section{Missing implants}

In the ten-year reporting period of this study there were only two reports of device expulsion and, even then, there was some doubt about these two cases being true extrusions because of lack of information in the reports. This is consistent with the understanding that extrusions/expulsions of etonogestrel implants are rare causes of pregnancy and that spontaneous expulsion of a device after correct insertion is close to impossible ${ }^{25}$. Studies showing expulsion rates above zero have all been on levonorgestrel multiple-rod implants ${ }^{26}$. Factors that have been proposed as predisposing to expulsion with levonorgestrel implants are incomplete insertion, wound infection, instances where the insertion procedure is a reinsertion in the same site, physical activity or low body mass index. 
Non-insertion appears to be a more common phenomenon than extrusion. In our study, $30 \%$ of Implanon cases and $22 \%$ of Nexplanon cases were due to missing implants - that is, the implant could not be located at the time pregnancy was confirmed. Missing implants were a significant issue with Implanon ${ }^{6}$; the redesign to Nexplanon was intended to address this and facilitate their location ${ }^{16}$. The proportion of cases associated with Nexplanon was not significantly different than with Implanon, suggesting the problem remains essentially unaltered.

\section{Drug interactions}

There is accumulating evidence from published reports of pregnancies occurring after concomitant use of potent enzyme inducers (see Table 2). In this study, known drug-drug interactions were identified in $10 \%$ of Implanon cases and $4 \%$ of Nexplanon cases. While the proportion of these pregnancies was numerically lower for Nexplanon, the difference between the groups was not significant (see Table 1). Ongoing reports with both devices suggest that awareness of drug interactions among prescribers needs to be repeatedly reinforced.

\section{Table 2}

Published reports of drug interactions resulting in pregnancy with the etonogestrel implant

\begin{tabular}{|c|c|c|c|}
\hline Enzyme inducer group & Drug & Spontaneous reporting & Case reports \\
\hline 'Herbal' & St John's wort & Simon et $\mathrm{al}^{15}$ & \\
\hline Anti-tuberculous & Rifampicin & Simon et $\mathrm{al}^{15}$ & $\begin{array}{l}\text { Bacon \& Mina } \\
\text { Patni }^{28} \\
\text { Gbolade }^{29}\end{array}$ \\
\hline \multirow[t]{4}{*}{ Anti-epileptic } & Phenobarbitone & $\begin{array}{l}\text { Bensouda-Grimaldi et al }{ }^{14} \\
\text { Simon et } \mathrm{al}^{15}\end{array}$ & \\
\hline & Phenytoin & Simon et al $^{15}$ & \\
\hline & Carbamazepine & $\begin{array}{l}\text { Harrison-Woolrych \& } \text { Hill }^{13} \\
\text { Bensouda-Grimaldi et al }{ }^{14} \\
\text { Simon et al }{ }^{15}\end{array}$ & $\begin{array}{l}\text { Schindbek }{ }^{30} \\
\text { Lange }^{31}\end{array}$ \\
\hline & Oxcarbazepine & Simon et $\mathrm{al}^{15}$ & \\
\hline \multirow[t]{2}{*}{ Anti-retroviral } & Efavirenz & Simon et al ${ }^{15}$ & $\begin{array}{l}\text { Matiluko } \\
\text { Lakhi }^{33} \\
\text { McCarty et al } \\
\text { Leticee et } \mathrm{al}^{35}\end{array}$ \\
\hline & Nelfinavir & Simon et al $^{15}$ & \\
\hline
\end{tabular}




\section{Obesity}

Although information regarding body mass index was missing from most reports, in 27 cases (11 Implanon, 16 Nexplanon) the only reason identified for contraceptive failure was obesity. The current product information states that ${ }^{36}$ :

- plasma levels of etonogestrel are inversely related to body weight and decrease over time

- although clinical experience is limited, the contraceptive effect in heavier women during the third year of use may be lower than for women of normal weight

- earlier replacement of the implant in heavier women may need to be considered.

Professional guidance points out that no increased risk of pregnancy has been demonstrated in women weighing up to $149 \mathrm{~kg}^{37}$. This guidance also states that plasma levels high enough to block ovulation are not the only parameter that should be taken into consideration, as the method has other contraceptive mechanisms of action ${ }^{37}$. In clinical trials, in which there was a zero failure rate, 175 of 1,716 women (10\%) weighed $70 \mathrm{~kg}$ or more, of whom 102 continued use beyond two years ${ }^{1}$. Also, in the CHOICE study, failure rates did not vary by body mass index ${ }^{38}$.

Almost half of these pregnancies (13 of 27 Nexplanon reports) were reported within two years of insertion, but there was not enough data in the reports for a more thorough assessment. In nine of the obesity cases, the women were morbidly obese (BMI $>45 \mathrm{~kg} / \mathrm{m}^{2}$ or weight $>110 \mathrm{~kg}$ ). Thus, although no other factor could be identified for these pregnancies other than obesity, some could also be classified as true method failures. Therefore, because of the uncertainties mentioned, cases referring to obesity in this study were classified as true method failures in Table 1.

\section{Broken implants}

In four Nexplanon cases it was reported that the implant was damaged, and this was classified as the reason for device failure (see 'other' category in Table 1). There are very limited other published data on this issue, although a pharmaceutical company response to an earlier case report suggested that breakage of an implant should not result in implant failure ${ }^{39}$. Analysis of more cases of broken implants would be required to assess this further. 


\section{Self-removal}

Missing implants have previously been attributed to self-removal ${ }^{40}$ (although the number of cases is very small). There have also been isolated reports of unsuccessful ${ }^{41}$ and successful ${ }^{42}{ }^{43}$ self-removal of implants by the woman herself, after the implant had been in place for some time, not immediately after insertion, before the wound is fully healed. In this study, there were no reported cases of implant self-removal but this may be a phenomenon that is not spontaneously reported on Yellow Cards, as it is not a product problem or a clinician error.

\section{CONCLUSIONS}

\section{Main findings}

The results of this study show that the most common reason for reported failure of etonogestrel implants is true method failure, a diagnosis of exclusion after assessment of other possible reasons for unintended pregnancies. Other reasons identified for device failure in this series included missing devices. A key finding was that the proportion of devices reported missing at the time of failure was similar for Implanon and Nexplanon. Our assessments suggested that non-insertion of the implant was a reason for the missing products, which is consistent with previous studies ${ }^{13}$. One intended benefit of Nexplanon was a reduction of the risk of non-insertion ${ }^{21}$ (with introduction of a 'nextgeneration applicator') but it appears that this aim has not been achieved.

More work, including continuing education of clinicians doing insertions, is needed on the prevention of avoidable causes of unintended pregnancies (e.g., failure of insertion and drug interactions) associated with etonogestrel implants.

\section{Strengths and limitations}

The strengths of this study are: 
- The largest and most recent study to report post-marketing experience of etonogestrel contraceptive devices

- Detailed clinical assessment of several hundred reports provides important information about reasons for failure of etonogestrel devices in real-world use

- Independent study using nationwide data

The limitations of the study are:

- It is based entirely on spontaneous reporting data and could not assess overall rates of failure (i.e. per 100 woman-years of use) in real-life use, as utilisation data were not available for the full period of review

- The amount of information for assessment was insufficient on many reports, with proportionally more instances for Nexplanon, and these cases had to be excluded from the analyses

\section{Implications for clinical practice}

History-taking must always include a detailed drug history, including non-prescription medicines. Timing of insertion must be confined to days $1-5$ of the cycle, or other times as recommended in professional guidelines, or the woman must have been using effective contraception during the whole of the insertion cycle.

Palpation of the implant in the arm by clinicians has become routine in clinical practice. Nevertheless, women themselves should be strongly encouraged to palpate their arm after any dressing is taken off and report any difficulty in identifying the presence of the implant. Women using contraceptive implants need to be told that they should at all times be able to feel the implant in their arm and that they should question the suitability of concomitant prescribed medicines.

\section{Implications for policy-makers and manufacturers}

There is potential for greater avoidance of pregnancies associated with etonogestrel implant use. Policy-makers need to ensure that health budgets are adequate to fund clinician updating. Manufacturers should strive further in the design of applicators to minimise human factors interfering with the successful delivery of implants into the arm. 


\section{Acknowledgements}

We thank Dr Jane Woolley, MHRA, for her helpful comments on the manuscript. We also thank Professor Peter Thomas, Bournemouth University, for statistical advice.

This study was first presented as a poster at the $18^{\text {th }}$ Annual Meeting of the International Society of Pharmacovigilance, Geneva, Switzerland, November 2018.

\section{Contributors}

SR conceived the idea for this study. All three authors contributed to the study design. EC extracted the data. All three authors were involved in the data analysis. SR wrote the first draft of the manuscript and all three authors contributed to subsequent drafts. All three authors approved the final manuscript.

\section{Funding}

This research did not receive any specific grant from funding agencies in the public, commercial or not-for-profit sectors.

\section{Disclaimer}

The content is solely the responsibility of the authors and does not necessarily represent the official views of the UK Medicines and Healthcare products Regulatory Agency.

\section{Competing interests}

The first author has received fees for acting as a trainer and for giving lectures on behalf of companies that market contraceptive implants.

\section{Patient consent}

Not required. 


\section{Ethics approval}

Not necessary. All data accessed were anonymised.

\section{Provenance and peer review}

Not commissioned; externally peer reviewed.

\section{Data sharing statement}

No additional data are available. 


\section{References}

1. Croxatto HB, Mäkäräinen L. The pharmacodynamics and efficacy of Implanon. Contraception 1998;58:91S-97S.

2. NICE. Addendum to clinical guideline 30, long-acting reversible contraception (CG30.1). London: National Institute for Health and Care Excellence 2014.

3. Craik J, Rowlands S. Contraceptive devices for women: implants, intrauterine devices and other products. In: Harrison-Woolrych M, ed. Medicines for women. Cham: Springer 2015:227-70.

4. Rowlands S, Mansour D, Walling M. Intravascular migration of contraceptive implants: two more cases. Contraception 2017;95:211-14.

5. Singh M, Mansour D, Richardson D. Location and removal of non-palpable Implanon ${ }^{\circledR}$ implants with the aid of ultrasound guidance. J Fam Plann Reprod Health Care 2006;32:153-56.

6. Rowlands S. Legal aspects of contraceptive implants. J Fam Plann Reprod Health Care 2010;36:243-48.

7. Boucoiran I, Trastour C, Faraj L, et al. Pregnancy with Implanon: a report on three cases [in French]. Gynécologie Obstétrique \& Fertilité 2011;39:e52-e54.

8. Gwinnell E. Expulsion of Implanon ${ }^{\circledR}$. J Fam Plann Reprod Health Care 2007;33:211.

9. Chaudhry F. Adverse reaction to Nexplanon ${ }^{\circledR}$. J Fam Plann Reprod Health Care 2013;39:231-32.

10. Mansour D. Comment on 'Adverse reaction to Nexplanon ${ }^{\circledR 1}$. J Fam Plann Reprod Health Care 2013;39:232.

11. Partridge R, Bush J. Infections post-Nexplanon insertion. J Fam Plann Reprod Health Care 2013;39:309-10.

12. Shah A, Lam V, Borahay MA, et al. A foreign body reaction to a contraceptive implant. J Women's Health \& Gynecology 2014;1:1-3.

13. Harrison-Woolrych M, Hill R. Unintended pregnancies with the etonogestrel implant (Implanon): a case series from postmarketing experience in Australia. Contraception 2005;71:306-08.

14. Bensouda-Grimaldi L, Jonville-Bera AP, Beau-Salinas F, et al. Insertion problems, removal problems and contraception failures with Implanon ${ }^{\circledR}$ [in French]. Gynécologie Obstétrique \& Fertilité 2005;33:986-90.

15. Simon C, Agier MS, Béné J, et al. Safety profile of etonogestrel contraceptive implant (Nexplanon and Implanon) reported in France [in French]. Journal de Gynécologie Obstétrique et Biologie de la Reproduction 2016;45:1074-82. 
16. Mansour D, Mommers $E$, Teede $H$, et al. Clinician satisfaction and insertion characteristics of a new applicator to insert radiopaque Implanon: an open-label, noncontrolled, multicenter trial. Contraception 2010;82:243-49.

17. Mansour D. UK provision for removal of non-palpable contraceptive implants. J Fam Plann Reprod Health Care 2009;35:3-4.

18. Davis S, King B, Raine JM. Spontaneous reporting - United Kingdom. In: Andrew EB, Moore N, eds. Mann's pharmacovigilance. 3rd ed. New York: Wiley Blackwell 2014.

19. Raine JM, Nooney JM. A medicines regulatory perspective on women's medicines. In: HarrisonWoolrych M, ed. Medicines for women. Cham: Springer 2015:433-58.

20. Clinical Effectiveness Unit. Quick starting contraception. London: Faculty of Sexual \& Reproductive Healthcare, 2017.

21. Rowlands S, Sujan M-A, Cooke M. A risk management approach to the design of contraceptive implants. J Fam Plann Reprod Health Care 2010;36:191-95.

22. Wenck BCA, Johnston PJ. Implanon and medical indemnity: a case study of risk management using the Australian standard. Med J Aust 2004;181:117-19.

23. Rowlands S. 10 tips for safe practice with Nexplanon: Primary Care Women's Health Forum; 2016 [Available from: https://www.pcwhf.co.uk/documents/top-10-tips-for-safe-practice.pdf accessed 20 June 2018.

24. Pearson S, Stewart M, Bateson D. Implanon NXT: expert tips for best-practice insertion and removal. AFP 2017;46:104-08.

25. Fraser IS. The challenges of location and removal of Implanon ${ }^{\circledR}$ contraceptive implants. J Fam Plann Reprod Health Care 2006;32:151-52.

26. Brache V, Faundes A, Alvarez F, et al. Nonmenstrual adverse events during use of implantable contraceptives for women: data from clinical trials. Contraception 2002;65:63-74.

27. Bacon L, Mina M. Letter to the Editor. Contraception 2006;73:111.

28. Patni S, Ebden P, Kevelighan E, et al. Ectopic pregnancy with Implanon ${ }^{\circledR}$. J Fam Plann Reprod Health Care 2006;32:115.

29. Gbolade BA. Failure of Implanon ${ }^{\circledR}$ on antituberculous therapy. Open Access Journal of Contraception 2010;1:103-05.

30. Schindbeck C, Janni W, Klaus F. Failure of Implanon contraception in a patient taking carbamazepine for epilepsia. Arch Gynecol Obstet 2006;273:255-56.

31. Lange J, Teal S, Tocce K. Decreased efficacy of an etonogestrel implant in a woman on antiepileptic medications: a case report. J Med Case Reports 2014;8:43. 
32. Matiluko AA, Soundararjan L, Hogston P. Early contraceptive failure of Implanon in an HIVseropositive patient on triple antiretroviral therapy with zidovudine, lamivudine and efavirenz. J Fam Plann Reprod Health Care 2007;33:277-78.

33. Lakhi N, Govind A. Implanon failure in patients on antiretroviral medication: the importance of disclosure. J Fam Plann Reprod Health Care 2010;36:181-82.

34. McCarty EJ, Keane H, Quinn K, et al. Implanon failure in an HIV-positive woman on antiretroviral therapy resulting in two ectopic pregnancies. Int J STD AIDS 2011;22:413-14.

35. Leticee N, Viard J, Yamgnane A, et al. Contraceptive failure of etonogestrel implant in patients treated with antiretrovirals including efavirenz. Contraception 2012;85:425-27.

36. MSD. Nexplanon 68mg implant for subdermal use. Summary of Product Characteristics: E Medicines Compendium; 2016 [Available from:

https://www.medicines.org.uk/emc/product/5720 accessed 16 January 2019.

37. Clinical Effectiveness Unit. Progestogen-only implants. London: Faculty of Sexual and Reproductive Healthcare 2014.

38. Xu H, Wade JA, Peipert JF, et al. Contraceptive failure rates of etonogestrel subdermal implants in overweight and obese women. Obstet Gynec 2012;120:21-26.

39. Rekers H. Removal of a fractured Nexplanon ${ }^{\circledR}$ : MSD response. J Fam Plann Reprod Health Care 2013;39:67.

40. Mansour D. Nexplanon ${ }^{\circledR}$ - what Implanon did next. J Fam Plann Reprod Health Care 2010;36:18789.

41. Gbolade BA. Attempted self-removal of Implanon: a case report. Asian Pacific Journal of Reproduction 2015;4:247-48.

42. Jaffer K, Whalen S. Self removal of Implanon ${ }^{\circledR}$ : a case report. J Fam Plann Reprod Health Care 2005;31:248.

43. Shepherd DJ. Self-removal of a contraceptive implant (letter). J Fam Plann Reprod Health Care 2012;38:208. 